\title{
Epidemiology and clinical features of coronavirus disease 2019 in children
}

\begin{abstract}
Soo-Han Choi, MD, PhD ${ }^{1}$, Han Wool Kim, MD, PhD², Ji-Man Kang, MD, PhD ${ }^{3,4}$, Dong Hyun Kim, MD , Eun Young Cho, MD
${ }^{1}$ Department of Pediatrics, Hallym University Dongtan Sacred Heart Hospital, Hallym University College of Medicine, Hwaseong, Korea; ${ }^{2}$ Department of Pediatrics, Hallym University Sacred Heart Hospital, Hallym University College of Medicine, Anyang, Korea; ${ }^{3}$ Department of Pediatrics, Severance Children's Hospital, Yonsei University College of Medicine, Seoul, Korea; ${ }^{4}$ Institute for Immunology and Immunological Diseases, Yonsei University College of Medicine, Seoul, Korea; ${ }^{5}$ Department of Pediatrics, Inha University Hospital, Inha University School of Medicine, Incheon, Korea; ${ }^{6}$ Department of Pediatrics, Chungnam National University Hospital, Daejeon, Korea
\end{abstract}

Coronavirus disease-2019 (COVID-19), which started in Wuhan, China, in December 2019 and declared a worldwide pandemic on March 11, 2020, is a novel infectious disease that causes respiratory illness and death. Pediatric COVID-19 accounts for a small percentage of patients and is often milder than that in adults; however, it can progress to severe disease in some cases. Even neonates can suffer from COVID-19, and children may spread the disease in the community. This review summarizes what is currently known about COVID-19 in children and adolescents.

Key words: Coronavirus, COVID-19, Child, Infant, Newborn

\section{Introduction}

In December 2019, a cluster of patients with pneumonia of unknown etiology were identified in Wuhan, China. A previously unknown betacoronavirus was detected in respiratory samples from the patients. ${ }^{1)}$ The virus was named severe acute respiratory syndrome coronavirus 2 (SARS-CoV-2) and was deemed caused by coronavirus disease 2019 (COVID-19). ${ }^{2)}$ COVID-19 rapidly swept mainland China and spread worldwide, causing 118,319 confirmed cases and 4,292 deaths in 113 nations as of March 11, 2020. The World Health Organization (WHO) declared COVID-19 a pandemic.3) In the Republic of Korea, starting with a Chinese traveler from Wuhan in January $20,{ }^{4)} 7,755$ confirmed cases leading to 60 deaths have occurred as of March 11, 2020.5)

COVID-19 is a novel infectious disease that is forecasted to have an enormous effect worldwide. This article reviews what is known about COVID-19 in children and adolescents as of March 12, 2020 in an effort to help clinicians managing pediatric cases.

\section{Epidemiology in children}

Published data on COVID-19 focuses primarily on adults, and the infection rate of COVID-19 in children is relatively low. ${ }^{6}$ The first pediatric case was reported on January 20, 2020, in a 10-year-old boy from Shenzhen, China, whose family had visited Wuhan City. ${ }^{7)}$ However, a retrospective study that enrolled 366 children ( $\leq 16$ years of age) hospitalized for respiratory infections between January 7 and 15, 2020 showed that COVID-19 was confirmed in 6 children (1.6\%) whose onset of illness occurred between January 2 and 8, 2020. This study result suggests that SARS-CoV-2 infections in children were occurring early on in the epidemic. $^{8)}$

Limited data are available on prevalence of COVID-19 in pediatric populations because children were rarely tested for the virus in earlier phase of the outbreak, especially in Hubei Province in China, where the most cases were confirmed. ${ }^{9)}$ Until January 31, 2020, of 11,791 confirmed COVID-19 cases in mainland China, 74 cases of pediatric patients $(0.6 \%)$ aged 1.5 months to 18 years were reported; 56\% (34 of 61) of them had a history of household contact. ${ }^{10)}$ Through February 7, 2020, although the data were incomplete, 285 pediatric cases of $34,546(0.8 \%)$ confirmed patients were documented, and 71.2\% (183 of 257) of infected children reported having household contact. ${ }^{11)}$ The youngest affected patient was a 36-hour-old newborn, who remains the youngest COVID-19 patient worldwide. ${ }^{12)}$ As of February 11, 2020, the Chinese Center for Disease Control and Prevention reported 44,672 laboratory-confirmed cases; 416 cases $(0.9 \%)$ were aged $0-9$ years, and 549 (1.2\%) were aged 10-19 years; 1 death occurred in the 10-19 years age group, and fatality rate in this group was $0.18 \% .{ }^{13)}$ According to a report from the WHO-China Joint Mission on COVID-19, the largestscale report to date, 55,924 cases were laboratory-confirmed by February 20, 2020. The median patient age was 51 years (range, 2 days to 100 years; interquartile range, 39-63 years); $2.4 \%$ of the affected patients were children under 19 years of age. Among

Corresponding author: Eun Young Cho, MD. Department of Pediatrics, Chungnam National University Hospital, 282 Munhwa-ro, Jung-gu, Daejeon 35015, Korea 凶E-mail: eycho@cnuh.co.kr, pedeyc@gmail.com, https://orcid.org/0000-0002-2286-4593

Received: 2 April, 2020, Accepted: 6 April, 2020

This is an open-access article distributed under the terms of the Creative Commons Attribution Non-Commercial License (http://creativecommons.org/licenses/bync/4.0/) which permits unrestricted non-commercial use, distribution, and reproduction in any medium, provided the original work is properly cited.

Copyright (c) 2020 by The Korean Pediatric Society 
children, $2.5 \%$ were severely ill and $0.2 \%$ were critical. $\left.{ }^{6}\right)$

By February 10, 2020, a total of 10,924 adult cases and 398 pediatric cases were confirmed in mainland China, excluding the Hubei Province. The rate of pediatric cases was 3.5\% (398 of 11,322).9 In 6 northern Chinese provinces, 31 children were diagnosed with COVID-19 between January 15 and February 21,2020 . The median pediatric patient age was 7.1 years (range, 6 months to 17 years); 21 children (68\%) had a history of contact with a confirmed adult patient, while 28 children (90\%) had an infected family member. ${ }^{14)}$

Pediatric COVID-19 cases outside of China have been sporadically reported, but limited data are available. Two Malaysian boys aged 2 years and 11 years on January $25,{ }^{15)}$ a German boy on January 31, ${ }^{16)}$ a Singaporean 6-month-old boy on February $5,{ }^{17,18)}$ and a Vietnamese 3-month-old infant on February 119) were reported. All of these cases involved exposure to an infected family member.

In Singapore, after an index case from China was first diagnosed with COVID-19 on January 23, 2020, the infection spread through community transmission. By March 11, 2020, 167 patients were confirmed to have COVID-19, 6 (3.6\%) of whom were children who were 6 months, 1 year, 2 years, 5 years, 12 years, and 17 years of age. Three children were residents of Wuhan; 2 children had an infected family member, and 1 reported exposure to an adult patient. ${ }^{17)}$ In Italy, in which a rapid increase in confirmed COVID-19 cases ensued after the cluster cases on February 21, 2020, a total of 8,342 cases had been reported by March 9, 2020; 1.4\% of cases were in children aged 0-18 years, among whom there were no fatalities. ${ }^{20)}$ In Australia, a total of 71 COVID-19 cases were confirmed by March 7, 2020 ; 2 cases were diagnosed in the $0-9$ years age group and 2 in the 10-19 years age group; therefore, $5.6 \%$ of the confirmed cases were in the $0-19$ years age group ${ }^{21)}$ (Table 1 ).

In Korea, a 10-year-old girl whose mother and uncle had been diagnosed with COVID-19 was the first pediatric case, reported on February 18, 2020.22) Thereafter, newspapers reported a 4-year-old on February 23,23) a 45-day-old infant on February $29,{ }^{24)}$ and a 4-week-old newborn on March 8. ${ }^{25}$ The 4-yearold was in contact with an infected daycare teacher, while the 45-day-old and the 4-week-old each were in contact with an infected family member.

As of midnight March 11, 2020, a total of 7,755 patients had confirmed disease, of whom 75 (1.0\%) were aged 0-9 years and 405 (5.2\%) were aged 10-19 years. No fatalities have been reported in these age groups. The COVID-19 incidence rate in Korea is calculated as 15.0 per 100,000 in all ages, 1.8 per 100,000 in ages $0-9$ years, and 8.2 per 100,000 in ages $10-19$ years according to national population data in February 2020 $(51,844,627$ overall, $4,134,824$ in the ages $0-9$ years group, and $4,920,794$ in the ages 10-19 years group). ${ }^{5,26}$ As of March 11, 2020, according to the pediatric age group analysis by school years performed by the Korea Centers for Disease Control and Prevention, 23 affected children were 0-2 years, 26 were 3-6 years, 82 were $7-12$ years, 78 were $13-15$ years, and 123 were $16-18$ years (Fig. 1). ${ }^{27)}$

\section{Clinical features in children}

It is known that children with COVID-19 show milder symptoms than adults, ${ }^{11)}$ but limited data exist on the burden of COVID-19 in children. A 10-year-old boy from Shenzhen, the first pediatric COVID-19 patient, was asymptomatic but displayed ground-glass opacity on an initial computed tomography (CT) scan. ${ }^{7}$ Another study analyzed 10 laboratory-confirmed Chinese pediatric cases in Shanghai, Hainan, Hefei, and Quindao between January 19 and February 3, 2020; the median patient age was 74 months (range, 3-131 months). Fever was noted in 8 , cough in 6 , sore throat in 4 , stuffy nose in 3 , and rhinorrhea in 2 children. The fevers were $37.7^{\circ} \mathrm{C}-39.2^{\circ} \mathrm{C}$ and resolved within 24 hours. Patchy infiltrations were observed on the chest CT scans of 4 patients. None of the 10 patients

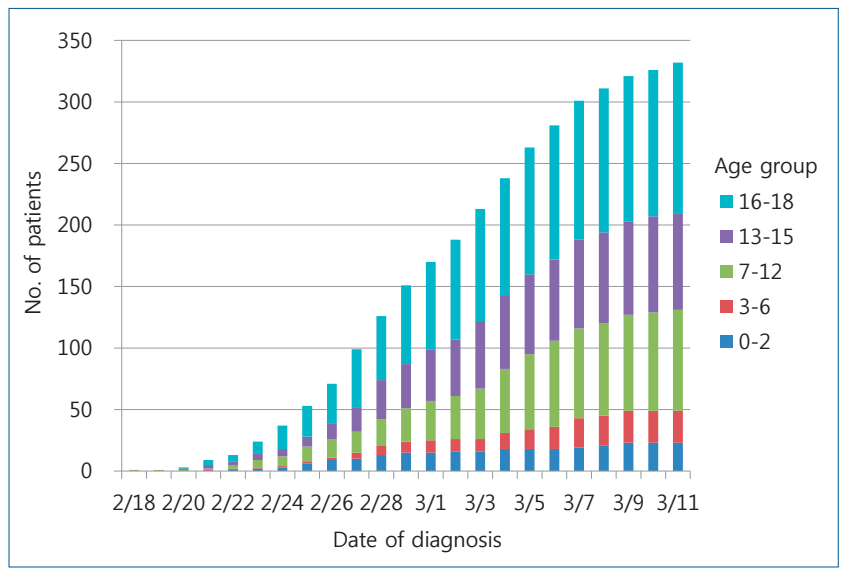

Fig. 1. Cumulative numbers of pediatric diagnoses of coronavirus disease 2019 in Korea by age group.

Table 1. Summary of epidemiology studies of pediatric cases of coronavirus disease 2019

\begin{tabular}{|c|c|c|c|c|c|c|c|c|}
\hline \multirow{2}{*}{ Variable } & \multicolumn{8}{|c|}{ Study area } \\
\hline & China $^{10)}$ & China $^{11)}$ & China $^{13)}$ & China $^{6)}$ & Singapore ${ }^{17)}$ & Italy ${ }^{20)}$ & Australia ${ }^{21)}$ & Republic of Korea $^{5}$ \\
\hline Study period & 31 Jan, 2020 & 7 Feb, 2020 & $\sim 11$ Feb, 2020 & $\sim 20$ Feb, 2020 & $\sim 11$ Mar, 2020 & 9 Mar, 2020 & 7 Mar, 2020 & $11 \mathrm{Mar}, 2020$ \\
\hline $\begin{array}{l}\text { Total confirmed } \\
\text { patients }\end{array}$ & 11,791 & 34,546 & 44,672 & 55,924 & 167 & 8,342 & 71 & 7,755 \\
\hline $\begin{array}{l}\text { Age and numbers } \\
\text { (proportion) of } \\
\text { children }\end{array}$ & $\begin{array}{l}1.5 \text { months- } \\
18 \text { years, } \\
74(0.6 \%)\end{array}$ & $\begin{array}{c}\text { Pediatric } \\
\text { (youngest: } \\
36 \mathrm{hr}), 285 \\
(0.8 \%)\end{array}$ & $\begin{array}{c}0-9 \text { years, } 416 \\
(0.9 \%) / 10-19 \\
\text { years, } 549 \\
(1.2 \%)\end{array}$ & $\begin{array}{c}\text { 0-18 years, } \\
(2.4 \%)\end{array}$ & $\begin{array}{l}6 \text { months- } \\
17 \text { years, } \\
6(3.6 \%)\end{array}$ & $\begin{array}{c}\text { 0-18 years, } \\
(1.4 \%)\end{array}$ & $\begin{array}{l}0-9 \text { years, } 2 \\
(2.8 \%) / 10-19 \\
\text { years, } 2(2.8 \%)\end{array}$ & $\begin{array}{c}\text { 0-9 years, } 75 \\
(1.0 \%) / 10-19 \\
\text { years, } 405(5.2 \%)\end{array}$ \\
\hline
\end{tabular}


required oxygen therapy. ${ }^{28)}$ Another study described 9 infants (age range, 1-11 months) in China outside of Hubei Province. Among the 7 infants who reported symptoms, 4 had fever, 2 had mild respiratory symptoms, and 1 was asymptomatic; no severe complications were noted. ${ }^{29)}$

In a study that enrolled 31 pediatric patients from 6 northern Chinese provinces between January 25 and February 21, 2020, 4 cases (12.9\%) were asymptomatic, 13 (41.9\%) were mildly symptomatic with normal radiography findings, 14 (45.2\%) had pneumonia, and none had severe illness. Ten of the 31 patients (32.3\%) complained of fever over $38^{\circ} \mathrm{C}$, and 10 (32.3\%) had a mild fever of $37.3^{\circ} \mathrm{C}-38^{\circ} \mathrm{C}$. The fever lasted $1-9$ days and subsided within 3 days in 15 patients (75\%). Fourteen (45.2\%) had a dry cough, 3 experienced fatigue, 3 had headache or dizziness, 2 had rhinorrhea, and 2 had a sore throat. One of the patients reported having a sore throat only, and 3 patients initially presented with diarrhea but without vomiting. ${ }^{14)}$

To date, 2 studies have described chest CT findings of pediatric patients in detail. ${ }^{30,31)}$ One study analyzed 15 pediatric COVID-19 cases admitted to a hospital in Shenzhen, China, between January 16 and February 6, 2020. The median patient age was 7 years (range, 4-14 years). At the time of diagnosis, 5 patients complained of fever, 1 had a cough, 1 had nasal congestion, and 8 (53.3\%) were asymptomatic. The leukocyte count was decreased in 8 (53.3\%) and within the normal range in 7 children. At the time of diagnosis, the chest CT scan revealed ground-glass opacity in $9(60 \%)$ and appeared normal in 6 patients. A follow-up CT performed after 3-5 days showed the development of new inflammatory lesions with ground-glass opacity in 3 of 9 patients whose SARS-CoV-2 polymerase chain reaction (PCR) results continued to be positive. Among the 6 patients whose PCR results became negative, the follow-up chest CT findings improved in $2 .^{30)}$

A study reported 20 pediatric COVID-19 patients admitted to the Wuhan Children's Hospital in China between January 23 and February 8, 2020. The median patient age was 2.1 years (range, 1 day to 14.6 years), and 3 neonates were included in the study. Thirteen patients complained of cough, 12 had a fever over $37.3^{\circ} \mathrm{C}, 3$ had diarrhea, 3 had rhinorrhea, and 2 had tachypnea. Respiratory crackles were auscultated in 3 patients, chest retraction was observed in 1 , and cyanosis was observed in 1. Most patients presented with signs of pneumonia. The leukocyte count was within the normal range in $14(70 \%)$, decreased in 4 (20\%), and increased in 2 patients (10\%). The percentage of lymphocytes was decreased in $7(35 \%)$ and increased in 3 patients (15\%). C-reactive protein was increased in $9(45 \%)$, and procalcitonin was increased in 16 patients (80\%). Eight patients (40\%) were coinfected with influenza A or B virus, Mycoplasma pneumoniae, respiratory syncytial virus, or cytomegalovirus. The initial chest CT scan showed unilateral pulmonary lesions in 6 (30\%), bilateral pulmonary lesions in 10 (50\%), and no abnormality in 3 neonates and 1 child (4 of 20, 20\%). All 20 children displayed subpleural lesions with localized inflammatory infiltration, 10 (50\%) showed consolidation with surrounding halo sign, 12 (60\%) showed ground-glass opacity, $4(20 \%)$ showed a fine mesh shadow, and 3 (15\%) showed tiny nodules. $^{31)}$

The first severe pediatric case reported was a 13-month-old boy admitted to Wuhan Children's Hospital on January 27, 2020. He presented with pneumonia, shock, acute respiratory distress, and renal failure at the time of admission. The patient had no known medical comorbidities; he had reportedly been treated at a local clinic for the past 6 days for intermittent diarrhea and vomiting but had no respiratory symptoms. He showed fever, dyspnea, and oliguria at the time of admission and received intensive care including intubation and mechanical ventilation. After treatment, he recovered gradually. ${ }^{32}$

The largest-scale report to date on COVID-19 in children examined 134 patients whose clinical data were available among 285 pediatric cases diagnosed in China as of February 7, 2020. The most common symptoms were fever and cough; other clinical features included fatigue, myalgia, rhinorrhea, nasal congestion, sore throat, headache, dizziness, nausea, vomiting, abdominal pain, and diarrhea. The symptoms mostly resolved within a week. Among the 117 children whose body temperatures were recorded, 89 (76.1\%) had a fever that lasted usually 1-2 days but up to 8 days. Complete blood counts were within the normal range in most patients; 2 showed a decreased leukocyte count, while 1 showed a slight decrease in lymphocyte count. C-reactive protein was normal or temporarily increased ( $>20 \mathrm{mg} / \mathrm{L}$ in 3 patients). When the 134 cases were classified by symptoms and chest radiology findings, 9 patients (6.7\%) were asymptomatic with normal chest radiology findings, 87 (64.9\%) had mild symptoms with normal chest radiology findings, 36 (26.9\%, including 7 subclinical patients) had pneumonia, and $2(1.5 \%)$ were critically ill (both of whom were mechanically ventilated). One of the critically ill patients was moderately malnourished and had a history of cardiac surgery for treating a congenital heart disease, while the other had hydronephrosis and a left renal stone. Among 54 patients for whom chest radiology data were available, 38 displayed ground-glass opacity or exudative/infiltrative lesions; of those, 7 were subclinical, 4 displayed increased pulmonary markings, and 12 showed no abnormalities. ${ }^{11)}$

In addition to the studies on clinical manifestations of COVID19 , one study analyzed pathogens retrieved from hospitalized children with respiratory infections during the early COVID-19 outbreak in Wuhan, China. Among the 366 children ( $\leq 16$ years of age) admitted to 3 hospitals in Wuhan between January 7 and 15, 2020, 43 (11.7\%) were infected with influenza A or B, while $6(1.6 \%)$ were infected with SARS-CoV-2. Children with COVID-19 were aged 1-7 years. All 6 children had fever over $39^{\circ} \mathrm{C}$ (duration, 3-11 days; median, 6 days) and cough, and 4 of them had vomiting. The chest CT scans showed pneumonia in 4 patients. One patient, a 3-year-old in whom ground-glass opacity was noted on the chest $\mathrm{CT}$ scan, received intensive care including oxygen therapy. The median length of stay was 7.5 days (range, 5-13 days), and all patients recovered. ${ }^{8)}$ 
In summary, children with COVID-19 most commonly present with fever, cough, and fatigue along with nasal stuffiness, rhinorrhea, sputum, diarrhea, and headache. Patients may be afebrile or present with a mild fever; fever subsides within 1-2 weeks in most cases. Dyspnea and cyanosis can occur as the condition progresses, usually after 1 week of the disease and accompanied by systemic symptoms such as malaise or restlessness, poor feeding, poor appetite, and decreased activity. Pneumonia may develop; in some cases, it rapidly progresses and may cause respiratory failure that cannot be corrected by conventional oxygen therapy within 1-3 days. In severe cases, septic shock, metabolic acidosis, and irreversible bleeding and coagulation dysfunction might occur. ${ }^{33,34)}$ Ground-glass opacity and subpleural lesions were commonly observed on the chest CT scans (Table 2). ${ }^{30,31)}$
In Korea, a case report on the first COVID-19 pediatric patient is the only known academic publication in children to date. A 10-year-old girl presented with a mild fever $\left(37.3^{\circ} \mathrm{C}\right)$ and scarce amount of sputum. She tested positive for SARS-CoV-2. On the 4th day after symptom onset, the chest CT scan showed patchy nodular consolidations accompanied by ground-glass opacity. She did not require antiviral therapy and recovered after supportive care.22)

\section{Importance of managing children with COVID-19}

Numerous family clustering cases of COVID-19 have been reported in China. Of 1,836 cases that occurred in Guangdong and Sichuan Provinces, 1,308 were related to 344 clusters,

Table 2. Summary of studies on clinical manifestations of pediatric coronavirus disease 2019

\begin{tabular}{|c|c|c|c|c|c|c|c|}
\hline Variable & $\begin{array}{l}\text { Liu et al. }{ }^{8)} \\
\qquad(n=6)\end{array}$ & $\begin{array}{l}\text { Cai et al. }{ }^{28)} \\
\quad(n=10)\end{array}$ & $\begin{array}{l}\text { Wei et al. }{ }^{29)} \\
\qquad(n=9)\end{array}$ & $\begin{array}{l}\text { Wang et al. }{ }^{14)} \\
\qquad(n=31)\end{array}$ & $\begin{array}{l}\text { Feng et al. }^{30)} \\
\qquad(n=15)\end{array}$ & $\begin{array}{l}\text { Xia et al. }{ }^{31)} \\
(n=20)\end{array}$ & $\begin{array}{c}\text { Society of } \\
\text { Pediatrics, } \\
\text { Chinese Medical } \\
\text { Association }^{11)} \\
(n=134)\end{array}$ \\
\hline $\begin{array}{l}\text { Characteristics of the study } \\
\text { and study area }\end{array}$ & $\begin{array}{l}\text { Hospitalized children } \\
\text { with acute respiratory } \\
\text { infections in Wuhan, } \\
\text { China }\end{array}$ & $\begin{array}{c}\text { Outside Hubei in } \\
\text { China: Shanghai, } \\
\text { Hainan, Hefei, } \\
\text { Qingdao }\end{array}$ & $\begin{array}{l}\text { Infants outside } \\
\text { Hubei in China: } \\
\text { Beijing, Hainan, } \\
\text { Guangdong, Anhui, } \\
\text { Shanghai, } \\
\text { Zhejiang, Guizhou }\end{array}$ & $\begin{array}{l}\text { Outside Hubei in } \\
\text { China: Shaanxi, } \\
\text { Gansu, Ningxia, } \\
\text { Hebei, Henan, } \\
\text { Shandong }\end{array}$ & Shenzen, China & $\begin{array}{l}\text { Wuhan, China } \\
\text { (includes } 8 \text { co- } \\
\text { infections) }\end{array}$ & China (nationwide) \\
\hline Study period & 7 Jan-15 Jan, 2020 & $\begin{array}{c}19 \text { Jan-3 Feb, } \\
2020\end{array}$ & $\begin{array}{c}8 \text { Dec } 2019-6 \text { Feb } \\
2020\end{array}$ & $\begin{array}{l}25 \text { Jan-21 Feb, } \\
2020\end{array}$ & $\begin{array}{c}16 \text { Jan-6 Feb, } \\
2020\end{array}$ & 23 Jan-8 Feb, 2020 & 7 Feb, 2020 \\
\hline Male sex & $2(33.3 \%)$ & $4(40.0 \%)$ & $2(22.2 \%)$ & $15(48.4 \%)$ & $5(33.3 \%)$ & $13(65.0 \%)$ & \\
\hline Age, median (range) & $3 y r(1-7)$ & 6.2 yr (0.3-10.9) & $0.6 \mathrm{yr}(0.2-0.9)$ & $7.1 \mathrm{yr}(0.5-17)$ & 7 yr (4-14) & 2.1 yr (1 day-14.6 yr) & Youngest: $36 \mathrm{hr}$ \\
\hline Clinical classifications & & & NA & & & NA & \\
\hline Asymptomatic & $0(0.0 \%)$ & $0(0.0 \%)$ & & $4(12.9 \%)$ & $0(0 \%)$ & & $9(6.7 \%)$ \\
\hline $\begin{array}{l}\text { Acute upper respiratory } \\
\text { tract infection }\end{array}$ & $2(33.3 \%)$ & $6(60.0 \%)$ & & $13(41.9 \%)$ & $3(20.0 \%)$ & & $87(64.9 \%)$ \\
\hline Mild pneumonia & $3(50.0 \%)$ & $4(40.0 \%)$ & & $14(45.2 \%)$ & $12(80.0 \%)$ & & $36(26.9 \%)$ \\
\hline Severe pneumonia & $1(16.7 \%)$ & $0(0 \%)$ & & $0(0 \%)$ & $0(0 \%)$ & & $0(0 \%)$ \\
\hline Critical case & $0(0 \%)$ & $0(0 \%)$ & & $0(0 \%)$ & $0(0 \%)$ & & $2(1.5 \%)$ \\
\hline Clinical symptoms & & & 7 Available & & & & 117 Available \\
\hline Fever & $6(100 \%)$ & $8(80.0 \%)$ & $4(57.1 \%)$ & $20(64.5 \%)$ & $5(33.3 \%)$ & $12(60.0 \%)$ & $89(76.1 \%)$ \\
\hline Cough & $6(100 \%)$ & $6(60.0 \%)$ & $2(28.6 \%)$ & $14(45.2 \%)$ & $1(6.7 \%)$ & $13(65.0 \%)$ & NA \\
\hline Rhinorrhea/sneezing & $1(16.7 \%)$ & $2(20.0 \%)$ & $1(14.3 \%)$ & $2(6.5 \%)$ & NA & $3(15.0 \%)$ & NA \\
\hline Sore throat & NA & $4(40.0 \%)$ & NA & $2(6.5 \%)$ & NA & $1(5.0 \%)$ & NA \\
\hline Headache/dizziness & NA & NA & NA & $3(9.7 \%)$ & NA & NA & NA \\
\hline Diarrhea & NA & $0(0.0 \%)$ & NA & $3(9.7 \%)$ & NA & $3(15.0 \%)$ & NA \\
\hline Dyspnea/tachypnea & $1(16.7 \%)$ & $0(0.0 \%)$ & NA & $0(0.0 \%)$ & NA & $2(10.0 \%)$ & NA \\
\hline Laboratory findings & & & NA & & NA & & NA \\
\hline Lymphopenia & $6(100 \%)$ & $0(0 \%)$ & & $2(6.5 \%, 2 / 31)$ & & 7 (35.0\%) (<45\%) & \\
\hline $\begin{array}{l}\text { Elevated C-reactive pro- } \\
\text { tein }\end{array}$ & $\begin{array}{l}5(83.3 \%) \\
(>10 \mathrm{mg} / \mathrm{L})\end{array}$ & $\begin{array}{c}3(30.0 \%) \\
(>8.0 \mathrm{mg} / \mathrm{L})\end{array}$ & & $3(10.0 \%, 3 / 30)$ & & $7(35.0 \%)(>3 \mathrm{mg} / \mathrm{L})$ & \\
\hline Abnormal liver enzymes & $4(66.7 \%)$ & $\begin{array}{c}2(10.0 \%) \\
(\mathrm{AST}>40 \mathrm{U} / \mathrm{L})\end{array}$ & & $6(22.2 \%, 6 / 27)$ & & $\begin{array}{c}5(25.0 \%) \\
(A L T>40 \mathrm{IU} / \mathrm{L})\end{array}$ & \\
\hline $\begin{array}{l}\text { Chest computed tomogra- } \\
\text { phy finding }\end{array}$ & 5 Available & NA & NA & 30 Available & & & 54 Available \\
\hline Normal & $1(20.0 \%)$ & & & 16 (53.3\%) & $6(40.0 \%)$ & $4(20.0 \%)$ & 12 (22.2\%) \\
\hline Abnormal & $\begin{array}{c}4(80.0 \%): 3 \text { patchy } \\
\text { shadows in both } \\
\text { lungs, } 1 \text { patchy } \\
\text { ground-glass } \\
\text { opacities in both lungs }\end{array}$ & & & $\begin{array}{l}14(46.7 \%): 9 \\
\text { patchy ground- } \\
\text { glass shadows } \\
\text { and nodules }\end{array}$ & $\begin{array}{c}9(60.0 \%): 9 \\
\text { ground-glass } \\
\text { opacities }\end{array}$ & $\begin{array}{l}16 \text { (80.0\%): } 10 \\
\text { consolidation with } \\
\text { surrounding halo sign, } \\
12 \text { ground-glass } \\
\text { opacities, } 4 \text { fine mesh } \\
\text { shadow, } 3 \text { tiny nodules }\end{array}$ & $\begin{array}{c}42(77.8 \%): 38 \\
\text { ground-glass or } \\
\text { exudative/invasive } \\
\text { lesions, } 4 \text { increased } \\
\text { pulmonary } \\
\text { markings }\end{array}$ \\
\hline
\end{tabular}

ALT, alanine transaminase; AST, aspartate transaminase; NA, not available. 
most (78\%-85\%) of which occurred in families. According to a preliminary study ongoing in Guangdong, China, the secondary attack rate within a household is estimated to be $3 \%-10 \%{ }^{6}{ }^{6}$ Children primarily contract the disease through household exposure, and 56\%-90\% of infected children had an infected family member. ${ }^{10,11,14,28)}$

Children are usually diagnosed with COVID-19 after an exposure to an infected adult within or outside of the family circle; however, the source of infection could not be identified in some cases, while the diagnosis of a child preceded that of an adult in others. A 3-month-old child with confirmed COVID-19 on January 26, 2020, in Hubei Province was hospitalized with fever and found to have mild pneumonia on the chest CT scan. At the time of diagnosis, his parents were asymptomatic with negative SARS-CoV-2 PCR results. After 7 days of hospitalization of the infant, his father complained of fever and fatigue, while his mother was asymptomatic; both of his parents showed signs of pneumonia on the chest CT scan and had positive SARS-CoV-2 PCR results. It was undetermined whether the incubation period was shorter in the infant than in the parents or the virus was transmitted from the infant to the parents. ${ }^{9,35)}$ In the first severe case of a 13-month-old who developed pneumonia, shock, acute respiratory distress, and renal failure, the source of infection could not be identified. His parents were not tested for SARSCoV-2.2)

Influenza surveillance during the first 2 weeks of January 2020 in Wuhan City, in which the COVID-19 outbreak originated, indicated that SARS-CoV-2 was detected in adults but not in children. ${ }^{6}$ In an analysis of 365 COVID-19 cases confirmed till February 5, 2020, in Shenzhen, China, the pediatric infection rate rapidly increased from $2 \%$ (before January 24) to $13 \%$ (between January 25 and February 5) $(P<0.001)$. The possible reasons for this might be that exposure to SARS-CoV-2 was lower in children in the early course of the outbreak. Otherwise, children were less likely to be tested because of their mild presenting symptoms and signs, especially in the setting of limited resources in the early phase of the outbreak. ${ }^{36}$

Little is known about the duration of viral shedding in children, and the reported durations varied widely across patients and samples. A 6-month-old infant diagnosed in Singapore on February 4, 2020 was asymptomatic but tested positive for SARS-CoV-2 PCR on a nasopharyngeal sample; his mother previously had confirmed COVID-19 pneumonia. The blood PCR sample turned positive for SARS-CoV-2 on hospital day 2, when the patient had a fever of $38.5^{\circ} \mathrm{C}$ that resolved immediately. A series of daily nasopharyngeal samples for PCR revealed that viral load presented as a 1/cycle threshold that peaked at the time of diagnosis and decreased over time. Negative conversion was achieved on hospital day 17. Stool PCR on hospital day 2 was negative but turned positive on day 9. ${ }^{18)}$

In a study that enrolled 10 Chinese children in Shanghai, Hainan, Hefei, and Qingdao, symptoms appeared at a median 6.5 days (range, 2-10 days) from the onset of illness in the index case. Patients tested positive for SARS-CoV-2 PCR on a nasopharyngeal or throat swab 4-48 hours after symptom onset, while negative conversion was seen at a median 12 days (range, 6-22 days). Prolonged shedding of viral RNA in the feces was observed for 18-30 days in 5 patients. ${ }^{28)}$

In summary, the transmission of SARS-CoV-2 in children primarily occurs through contact with adult patients, mainly through household exposure. In contrast, direct transmission from a child to an adult has not been reported to date. However, the observation of prolonged detection of viral RNA in nasopharyngeal/throat swabs and feces of pediatric patients suggests that children and adolescents may be transmitters in the community.

\section{Considerations in pregnant women and newborns}

In the report of the WHO-China Joint Mission on COVID-19 patients diagnosed through February 20, 2020, pregnant women were not at higher risk for severe COVID-19. Of 147 (64 confirmed, 82 suspected, and 1 asymptomatic) pregnant women investigated, $8 \%$ had severe signs consisting of dyspnea and hypoxemia, while $1 \%$ was critical and required intensive care. ${ }^{6}$ However, pneumonia is one of the most common infections during pregnancy, as it may lead to premature rupture of the membranes, preterm labor, intrauterine growth retardation, and stillbirth. ${ }^{37-39)}$ Sporadic case reports on COVID-19 in pregnant women observed obstetric complications including stillbirth, preterm birth, and premature rupture of the membranes. ${ }^{40-43)}$ In a study of 9 pregnant women with COVID-19 diagnosed in Wuhan, China, from January 20 to 31, 2020, all women were infected at gestational age 36 weeks or later and delivered by caesarean section. Seven women complained of fever at the time of diagnosis, but none developed severe pneumonia that led to mechanical ventilation or death. Obstetrical complications included preterm deliveries in 4 and premature rupture of the membranes in 2; no cases of neonatal asphyxia or stillbirth were observed. From 6 patients, amniotic fluid, cord blood, breast milk, and neonatal throat swab samples were tested for SARSCoV-2; all were negative. ${ }^{40)}$ A case report from Suzhou, China, described a pregnant woman at 30 -week gestation. She was diagnosed with COVID-19 pneumonia on February 6, 2020 and delivered a $1.83-\mathrm{kg}$ preterm baby via emergency caesarean section due to fetal distress. SARS-CoV-2 PCR of the amniotic fluid, placenta, cord blood, neonatal gastric juice, and neonatal throat swab was negative. ${ }^{41)}$ A study analyzing 13 pregnant women with COVID-19 from December 8, 2019 to February 25, 2020 in mainland China outside of Wuhan included 2 women in their second trimester. Ten women had fever, 3 had dyspnea, and 1 was asymptomatic. Of the 13 women, 3 (23\%) recovered and were discharged with uncomplicated ongoing pregnancy; 10 delivered by caesarean section. Five women underwent emergency caesarean section due to fetal distress (3 cases), premature rupture of membrane (1 case), and stillbirth (1 
case). Six women had preterm labor. At 34-week gestation, one of the women developed acute respiratory distress syndrome and multiple organ failure requiring extracorporeal membrane oxygenation support; her baby was stillbirth. ${ }^{42)}$

In a report of 10 neonates born to 9 mothers with COVID-19 in Hubei, China, between January 20 and February 5, 2020, intrauterine distress was observed in 6 and premature rupture of the membranes was observed in 3. Six infants were born premature, 2 were small for gestational age, and 1 was large for gestational age. Clinical features of the newborns included shortness of breath (6 cases) and fever ( 2 cases). Two newborns developed thrombocytopenia complicated by abnormal liver function. One of the newborns was delivered at 34 weeks and 5 days' gestation, developed shock and multiple organ failure on day 8 , and died on day 9. Nine of the newborns underwent SARS-CoV-2 PCR testing on days 1-9; all were negative. ${ }^{44)}$ To date, there have been no reports of the vertical transmission of SARS-CoV-2. However, existing reports are incomplete because they included small sample sizes, primarily dealt with COVID-19 occurring in the third trimester, and not all pregnant women underwent SARS-CoV-2 PCR testing. Continuous monitoring is needed to assess the possibility of mother-to-child transmission.

To date, 3 cases of confirmed COVID-19 in neonates have been reported in Wuhan, China. ${ }^{11,12,31,45)}$ A neonate was diagnosed with COVID-19 at 36 hours after birth. His mother was at 40 weeks' gestation and developed a fever on February 1, 2020. The chest CT scan displayed ground-glass opacities sug. gestive of viral pneumonia. An emergency caesarean section was performed the same day and the newborn did not have contact with the mother after birth. The mother's SARS-CoV-2 PCR result was positive the next day. A pharyngeal swab collected from the newborn at 36 hours after birth later tested positive for SARS-CoV-2. However, the cord blood, placenta, and breast milk were negative for SARS-CoV-2. The newborn was afebrile with no coughing or vomiting; however, the chest CT scan showed a nodular shadow under the pleura on day 6 . The follow-up chest CT scan showed small patchy shadows on day 12 that improved on day 17. SARS-CoV-2 PCR conducted of pharyngeal and anal swabs on day 17 were negative and he was discharged on day $18 .{ }^{12)}$ Another 5 -day-old neonate with a fever was diagnosed with COVID-19, and his mother was diagnosed with COVID-19.11) A 17-day-old newborn was hospitalized on February 5, 2020 with a 1-week history of sneezing and vomiting. His parents were diagnosed with COVID-19 3 days prior. His chest CT scan showed increased pulmonary markings; all symptoms resolved by hospitalization day 7.45) A small number of neonatal COVID-19 have been reported to date, and the infected neonates had mild or no symptoms. However, current data support that neonates are susceptible to COVID-19; therefore, special precautions including hand hygiene are required of individuals in close contact with newborns (Table 3).

\section{Conclusion}

COVID-19 is a novel infectious disease that was recently declared a pandemic. It is rapidly spreading worldwide, infecting and killing thousands of people. Limited information is available on this previously unknown coronavirus that has been around for less than 3 months. It is known that children comprise a small fraction of COVID-19 cases, and their symptoms are often mild. However, some pediatric cases may progress to severe disease, and initial atypical presentations may delay the diagnosis of COVID-19, leading to unfavorable outcomes. It is worth

Table 3. Summary of studies on perinatal cases of coronavirus disease 2019

\begin{tabular}{|c|c|c|c|}
\hline Variable & Chen et al. ${ }^{40)}$ & Liu et al. ${ }^{42)}$ & Zhu et al. ${ }^{44)}$ \\
\hline Study area & Wuhan, China & Outside Wuhan, China & Hubei Province, China \\
\hline $\begin{array}{l}\text { No. of pregnant women cases (laboratory-confirmed } \\
\text { SARS-CoV-2) }\end{array}$ & 9 & 13 & 9 \\
\hline No. of births & 9 & 10 & 10 \\
\hline Study period & 20 Jan-31 Jan, 2020 & 8 Dec 2019-25 Feb, 2020 & 20 Jan-5 Feb, 2020 \\
\hline Maternal age (yr), median (range) & $28(26-40)$ & $30(22-36)$ & $30(25-35)$ \\
\hline Gestational age (wk), median (range) & 37 wk 2 days ( 36 wk-39 wk 4 days) & 35 wk ( 25 wk-38 wk 3 days) & 34 wk 6 days (31-39 wk) \\
\hline Maternal severe pneumonia & $0(0 \%)$ & $1^{\mathrm{a})}(7.7 \%)$ & NA \\
\hline Discharge without complication before delivery & $0(0 \%)$ & $3(23.1 \%)$ & $0(0 \%)$ \\
\hline \multicolumn{4}{|l|}{ Delivery-related information } \\
\hline Caesarean section & $9(100 \%)$ & $10(100 \%)$ & $7(77.8 \%)$ \\
\hline Preterm labor/delivery & $4(44.4 \%)$ & $6(60.0 \%)$ & $6(66.7 \%)$ \\
\hline Fetal distress & $2(22.2 \%)$ & $3(30.0 \%)$ & $6(66.7 \%)$ \\
\hline Premature rupture of the membranes & $2(22.2 \%)$ & $1(10.0 \%)$ & $3(33.3 \%)$ \\
\hline Stillbirth & $0(0 \%)$ & $1^{\text {a) }}(10.0 \%)$ & $0(0 \%)$ \\
\hline Neonatal asphyxia & $0(0 \%)$ & $0(0 \%)$ & $0(0 \%)$ \\
\hline Postnatal death & $0(0 \%)$ & $0(0 \%)$ & $1^{\mathrm{b})}(10.0 \%)$ \\
\hline
\end{tabular}

NA, not available; SARS-CoV-2, severe acute respiratory syndrome coronavirus 2.

a) The mother's condition deteriorated during hospitalization, requiring mechanical ventilation with extracorporeal membrane oxygenation support.

b) The neonate died of refractory shock and gastric bleeding. 
mentioning that newborns are susceptible to this disease and viruses are detected for a prolonged period; therefore, newborns might play a role in community transmission. There is currently no standard of management or prevention. Further investigation is needed to assess the reason for differences in clinical features of COVID-19 by age, evaluate the role of children in community transmission, and develop treatment and vaccines for the disease. We hope that current and future research on COVID-19 can answer these questions and look forward to wisely managing this crisis for mankind.

\section{Conflicts of interest}

No potential conflict of interest relevant to this article was reported.

\section{Acknowledgments}

We are grateful for the support of the members of the Korean Society of Pediatric Infectious Diseases, the Committee on Infectious Diseases of the Korean Pediatric Society, and the Korea Centers for Disease Control and Prevention.

This review article is published jointly by the Clinical and Experimental Pediatrics and the Pediatric Infection and Vaccine.

\section{References}

1. Zhu N, Zhang D, Wang W, Li X, Yang B, Song J, et al. A novel coronavirus from patients with pneumonia in China, 2019. N Engl J Med 2020; 382:727-33.

2. World Health Organization. Novel coronavirus (2019-nCoV). Situation report-22 [Internet]. Geneva (Switzerland): World Health Organization; 2020 [cited 2020 Mar 12]. Available from: https://www.who.int/docs/ default-source/coronaviruse/situation-reports/20200211-sitrep-22-ncov. pdf.

3. World Health Organization. Coronavirus disease 2019 (COVID-19). Situation report-51 [Internet]. Geneva (Switzerland): World Health Organization; 2020 [cited 2020 Mar 12]. Available from: https://www. who.int/docs/default-source/coronaviruse/situation-reports/20200311sitrep-51-covid-19.pdf.

4. Kim JY, Choe PG, Oh Y, Oh KJ, Kim J, Park SJ, et al. The first case of 2019 novel coronavirus pneumonia imported into Korea from Wuhan, China: implication for infection prevention and control measures. J Korean Med Sci 2020;35:e61.

5. Korea Centers for Disease Control and Prevention. The updates of COVID-19 in Republic of Korea, as of 11 March, 2020. Cheongju (Korea): Korea Centers for Disease Control and Prevention, 2020.

6. World Health Organization. Report of the WHO-China joint mission on COVID-19, 16-24 February 2020. Geneva (Switzerland): World Health Organization; 2020.

7. Chan JF, Yuan S, Kok KH, To KK, Chu H, Yang J, et al. A familial cluster of pneumonia associated with the 2019 novel coronavirus indicating personto-person transmission: a study of a family cluster. Lancet 2020;395:51423.

8. Liu W, Zhang Q, Chen J, Xiang R, Song H, Shu S, et al. Detection of COVID-19 in children in early January 2020 in Wuhan, China. N Engl J Med 2020;382:1370-1.

9. Cao Q, Chen YC, Chen CL, Chiu CH. SARS-CoV-2 infection in children: transmission dynamics and clinical characteristics. J Formos Med Assoc 2020;119:670-3.

10. Fang F, Luo XP. Facing the pandemic of 2019 novel coronavirus infections: the pediatric perspectives. Zhonghua Er Ke Za Zhi 2020;58:
81-5.

11. Society of Pediatrics, Chinese Medical Association; Editorial Board, Chinese Journal of Pediatrics. Recommendations for the diagnosis, prevention and control of the 2019 novel coronavirus infection in children (first interim edition). Zhonghua Er Ke Za Zhi 2020;58:169-74.

12. Wang S, Guo L, Chen L, Liu W, Cao Y, Zhang J, et al. A case report of neonatal COVID-19 infection in China. Clin Infect Dis 2020.

13. Novel Coronavirus Pneumonia Emergency Response Epidemiology Team. The epidemiological characteristics of an outbreak of 2019 novel coronavirus diseases (COVID-19) in China. Zhonghua Liu Xing Bing Xue ZaZhi 2020;41:145-51.

14. Wang D, Ju XL, Xie F, Lu Y, Li FY, Huang HH, et al. Clinical analysis of 31 cases of 2019 novel coronavirus infection in children from six provinces (autonomous region) of northern China. Zhonghua Er Ke Za Zhi 2020; 58:E011.

15. 3 coronavirus cases in Malaysia include 2-year-old boy. New Straits Times [Internet]. 2020 Jan 25; [cited 2020 Mar 12]. Available from: https:// www.nst.com.my/news/nation/2020/01/559584/3-coronavirus-casesmalaysia-include-2-year-old-boy.

16. Current information on the corona virus situation in Bavaria - Bavarian Ministry of Health: 8th case confirmed - 33-year-old man from Munich [Internet]. Munich (Germany): Bavarian State Ministry of Health and Care; 2020 Feb 1; [cited 2020 Mar 12]. Available from: https:/www. stmgp.bayern.de/presse/aktuelle-informationen-zur-coronavirus-lage-inbayern-bayerisches-gesundheitsministerium-8/.

17. Singapore Government Agency. COVID-19: cases in Singapore [Internet]. Singapore: Singapore Government Agency; 2020 [cited 2020 Mar 12]. Available from: https://www.gov.sg/article/covid-19-cases-in-singapore.

18. Kam KQ, Yung CF, Cui L, Lin Tzer Pin R, Mak TM, Maiwald M, et al. A well infant with coronavirus disease 2019 (COVID-19) with high viral load. Clin Infect Dis 2020; ciaa201.

19. Ministry of Health Vietnam. Situation of diseases, COVID-19, 11 Feb 2020 [Internet]. Hanoi (Vietnam): Ministry of Health Vietnam; 2020 [cited 2020 Mar 12]. Available from: https://ncov.moh.gov.vn/web/guest/ dong-thoi-gian.

20. Italian National Institute of Health. Integrated surveillance of COVID-19 in Italy, 09 Mar 2020 [Internet]. Rome (Italy): Italian National Institute of Health; 2020 [cited 2020 Mar 12]. Available from: https:/www.iss.it/ documents/20126/0/Infografica_09marzo.pdf/.

21. COVID-19 National Incident Room Surveillance Team. COVID-19, Australia: Epidemiology Report 6 (Reporting week ending 19:00 AEDT 7 March 2020). Commun Dis Intell (2018) 2020;44:10.33321/cdi.2020. 44.21.

22. Park JY, Han MS, Park KU, Kim JY, Choi EH. First pediatric case of coronavirus disease 2019 in Korea. J Korean Med Sci 2020;35:e124.

23. Kim BG. 4-year-old becomes youngest COVID-19 patient. The Korea Herald [Internet]. $2020 \mathrm{Feb} 23$; [cited $2020 \mathrm{Mar}$ 12]. Available from: http://www.koreaherald.com/view.php?ud=20200223000222.

24. Joo KD. 45-day-old baby infected with new coronavirus in S. Korea: authorities. Yonhap News Agency [Internet]. 2020 Mar 1; [cited 2020 Mar 12]. Available from: https://en.yna.co.kr/view/AEN20200301001500320.

25. Kim JH. 4-week-old newborn baby was confirmed in Dongdaemun-gu, Seoul: probably the nation's youngest. Yonhap News Agency [Internet]. 2020 Mar 8; [cited 2020 Mar 12]. Available from: https://www.yna.co.kr/ view/AKR20200308073500004.

26. Korean Statistical Information Service (KOSIS). Registered population by administrative district/year-old [Internet]. Daejeon (Korea): Statistics Korea; 2020 Feb; [cited 2020 Mar 12]. Available from: http://kosis.kr/ statHtml/statHtml.do?orgId=101\&tblId=DT_1B04006\&conn_path=I2.

27. Korea Centers for Disease Control and Prevention. Pediatric COVID-19 patients in Korea [unpublished data]. Cheongju (Korea): Korea Centers for Disease Control and Prevention, 2020.

28. Cai J, Xu J, Lin D, Yang Z, Xu L, Qu Z, Zhang Y, et al. A case series of children with 2019 novel coronavirus infection: clinical and epidemiological features. Clin Infect Dis 2020 Feb 28 [Epub]. pii: ciaa198. https:// doi.org/10.1093/cid/ciaa198.

29. Wei M, Yuan J, Liu Y, Fu T, Yu X, Zhang ZJ. Novel coronavirus infection 
in hospitalized infants under 1 year of age in China. JAMA $2020 \mathrm{Feb} 14$ [Epub]. https://doi.org/10.1001/jama.2020.2131.

30. Feng K, Yun YX, Wang XF, Yang GD, Zheng YJ, Lin CM, et al. Analysis of CT features of 15 children with 2019 novel coronavirus infection. Zhonghua Er Ke Za Zhi 2020;58:275-8.

31. Xia W, Shao J, Guo Y, Peng X, Li Z, Hu D. Clinical and CT features in pediatric patients with COVID-19 infection: Different points from adults. Pediatr Pulmonol 2020 Mar 5 [Epub]. https://doi.org/10.1002/ ppul.24718.

32. Chen F, Liu ZS, Zhang FR, Xiong RH, Chen Y, Cheng XF, et al. First case of severe childhood novel coronavirus pneumonia in China. Zhonghua Er Ke Za Zhi 2020;58:179-82.

33. Chen ZM, Fu JF, Shu Q, Chen YH, Hua CZ, Li FB, et al. Diagnosis and treatment recommendations for pediatric respiratory infection caused by the 2019 novel coronavirus. World J Pediatr 2020;10.1007/s12519-02000345-5.

34. Shen K, Yang Y, Wang T, Zhao D, Jiang Y, Jin R, et al. Diagnosis, treatment, and prevention of 2019 novel coronavirus infection in children: experts' consensus statement. World J Pediatr 2020;10.1007/s12519-020-003437.

35. Zhang YH, Lin DJ, Xiao MF, Wang JC, Wei Y, Lei ZX, et al. 2019 novel coronavirus infection in a three-month-old baby. Zhonghua Er Ke Za Zhi 2020;58:182-4.

36. Liu J, Liao X, Qian S, Yuan J, Wang F, Liu Y, et al. Community transmission of severe acute respiratory syndrome coronavirus 2, Shenzhen, China, 2020. Emerg Infect Dis 2020;26.
37. Benedetti TJ, Valle R, Ledger WJ. Antepartum pneumonia in pregnancy. Am J Obstet Gynecol 1982;144:413-7.

38. Berkowitz K, LaSala A. Risk factors associated with the increasing prevalence of pneumonia during pregnancy. Am J Obstet Gynecol 1990; 163:981-5.

39. Madinger NE, Greenspoon JS, Ellrodt AG. Pneumonia during pregnancy: has modern technology improved maternal and fetal outcome? Am J Obstet Gynecol 1989;161:657-62.

40. Chen H, Guo J, Wang C, Luo F, Yu X, Zhang W, et al. Clinical characteristics and intrauterine vertical transmission potential of COVID-19 infection in nine pregnant women: a retrospective review of medical records. Lancet 2020;395:809-15.

41. Wang X, Zhou Z, Zhang J, Zhu F, Tang Y, Shen X. A case of 2019 novel coronavirus in a pregnant woman with preterm delivery. Clin Infect Dis 2020; ciaa200.

42. Liu Y, Chen H, Tang K, Guo Y. Clinical manifestations and outcome of SARS-CoV-2 infection during pregnancy. J Infect $2020 \mathrm{Mar} 4$ [Epub]. https://doi.org/10.1016/j.jinf.2020.02.028.

43. Li Y, Zhao R, Zheng S, Chen X, Wang J, Sheng X, et al. Lack of vertical transmission of severe acute respiratory syndrome coronavirus 2, China. Emerg Infect Dis 2020;26:10.3201/eid2606.200287.

44. Zhu H, Wang L, Fang C, Peng S, Zhang L, Chang G, et al. Clinical analysis of 10 neonates born to mothers with $2019-\mathrm{nCoV}$ pneumonia. Transl Pediatr 2020;9:51-60.

45. Zeng LK, Tao XW, Yuan WH, Wang J, Liu X, Liu ZS. First case of neonate with COVID-19 in China. Zhonghua Er Ke Za Zhi 2020;58:279-80. 